\title{
Compaction Localization in Porous Sandstone: Implications for Reservoir Mechanics
}

\author{
W.A. Olsson ${ }^{1}$, D.J. Holcomb ${ }^{1}$ and J.W. Rudnicki ${ }^{2}$ \\ 1 Geomechanics Department Sandia National Laboratories, Albuquerque - New Mexico 87185-0751 \\ 2 Department of Civil Engineering Northwestern University, Evanston - Illinois 60208-3109 \\ waolsso@sandia.gov -djholco@sandia.gov - jwrudn@nwu.edu
}

Résumé - Zones de compaction localisée dans les grès poreux : conséquences sur l'écoulement dans les gisements - La compaction des roches poreuses peut se produire de deux façons : régulière et localisée. Des travaux d'essais récents ont démontré que la compaction peut se produire dans des zones tabulaires dont l'épaisseur s'accrôt avec la déformation de compression.

L'apparition de couches de compaction ainsi que leur croissance ont une forte influence sur la perméabilité mesurée de la roche. La roche se trouvant derrière le front mobile de compaction peut être compactée de manière régulière ou peut comporter des couches intercalées de matière non compactée et compactée. Ces trois types de compaction auraient des effets très différents sur les gisements subissant la compaction. Dans cet article, nous réexaminons l'état des résultats d'essais sur la compaction localisée et la théorie de bifurcation sur la localisation des déformations pour la compaction.

\begin{abstract}
Compaction Localization in Porous Sandstone: Implications for Reservoir Mechanics Compaction of porous rocks can occur in two modes: uniform and localized. Recent experimental work has demonstrated that compaction can occur in tabular zones that expand with increasing applied deformation. The appearance of compaction bands and their growth has a strong influence on the measured permeability of the host rock. The rock behind the moving compaction front can be either uniformly compacted or can consist of intercalated bands of uncompacted and compacted material. These three types of compaction would have very different effects on production from reservoirs undergoing compaction. We review the status of experimental results on localized compaction and the bifurcation theory of strain localization for compaction.
\end{abstract}




\section{INTRODUCTION}

Compaction of porous rock is an important process in the oil and gas industry. Compaction caused by changes in effective stresses during production can:

- cause casing failures;

- lead to seafloor subsidence having a significant impact on structure design and performance, and

- squeeze oil from the rock into the borehole, or

- significantly decrease the permeability of the reservoir rock thus reducing production (Ostermeier, 2001).

When grain crushing is involved, compaction may also contribute to sand production in boreholes (Haimson, 2001). Diagenesis is of course a natural arena where compaction plays an important role but this paper does not touch on that important problem.

Naturally occurring, nonhomogeneous compaction, arranged in subparallel, sharply restricted, or localized, layers, unrelated to sedimentary layering was described by Mollema and Antonellini (1966). They demonstrated that compaction had occurred in thin, tabular zones, approximately $1 \mathrm{~cm}$ thick, oriented perpendicular to the axis of maximum compression. These zones were characterized by pure normal compression and little or no shear displacement and were called compaction bands. Within the compaction bands porosity and grain size were reduced. Presumably, these compaction bands would be serious impediments to fluid flow because of reduced permeability. Related features, deformation bands, can be characterized by a component of compaction combined with added shear motion; they also have an impact on fluid flow (Antonellini and Aydin, 1995). The scope of this paper is restricted to compaction bands.

In a paper describing the first experimental attempt to reproduce compaction bands in the laboratory, Olsson (1999) suggested that previous laboratory experiments on physical models, blocks containing various shaped holes and subjected to boundary loads, created structures related to compaction bands. In blocks of plaster, Lajtai (1974) created what he called normal shear fractures in association with open slots inclined to the maximum compression, and round holes. These were bands of crushed plaster oriented perpendicular to the maximum compression. Bessinger et al. (1997) compressed bricks composed of glass beads that contained a central borehole. They observed what they called nondilatational fractures that were oriented normal to the direction of loading and radiated from the hole. These were tabular zones of crushed glass beads. In laboratory drilling experiments, Haimson and Song (1998) observed the formation of tabular zones of crushed grains that grew radially away from a borehole being drilled while the rock was under stress. The crushed grains were washed away by the circulating drilling fluid leaving open slots. They
(Haimson and Song, 1998) found these slots in Berea sandstone of $22 \%$ porosity. For Berea of $17 \%$ porosity, normal, $v$-shaped borehole breakouts formed, similar to those formed in low-porosity rock types such as limestone and granite.

They noted that other than the porosity there was no significant difference in composition or microstructure between the two Berea sandstones that they studied.

Olsson's (1999) triaxial (axisymmetric, confined compression) experiments were carried out on Castlegate sandstone having a porosity of $28 \%$. This rock is composed of $70-80 \%$ quartz grains of about $0.2 \mathrm{~mm}$ diameter, $5-10 \%$ clay, and a few rock fragments. For confining pressures below $69 \mathrm{MPa}$, well-developed shear bands, or faults, were formed just following the peak in the stress-strain curve. At confining pressures greater than $150 \mathrm{MPa}$ generalized, uniform compaction occurred during the hydrostatic portion of the experiment, and accelerated compaction occurred during yielding under superimposed shear stress. Over the confining pressure range of 69 to $100 \mathrm{MPa}$, compaction zones developed at one or both ends of the specimens. These compaction zones were about one-third the specimen length in thickness. He suggested (Olsson, 1999), based on stressstrain data from the experiments, that these compaction zones had grown to that length during axial shortening of the specimen. Olsson (1999) also showed that the strain localization theory of Rudnicki and Rice (1975) was applicable to compaction as well as to shear localization of strain. He derived what is now known to be an overly restrictive set of values of constitutive properties for the appearance of compaction bands in axisymmetric compression.

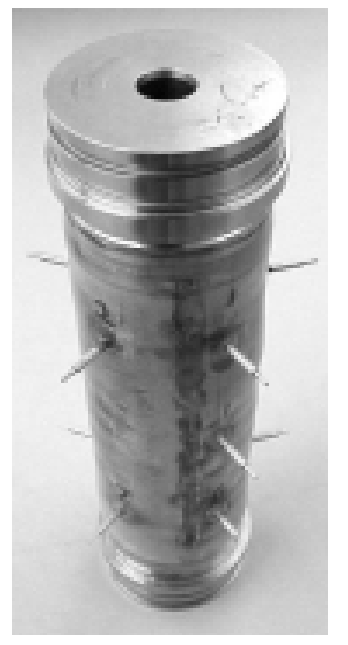

Figure 1

Photograph of sample showing ultrasonic transducers (pins protruding from sides of sample), copper and urethane coating and steel endcaps. 
New work on the theoretical foundations of compaction band formation has extended the space of constitutive parameters over which the bands can form (Issen and Rudnicki, 2000, 2001; Rudnicki, 2001). Besuelle (2001) draws attention to the fact that the theory actually predicts that the orientation of deformation bands can vary smoothly from parallel, through oblique, to perpendicular to the maximum compression direction. Thus the bifurcation theory of strain localization has the generality to encompass all deformation band orientations from extension bands (that may manifest themselves as extension fractures), through shear bands, to compaction bands.

\section{RECENT EXPERIMENTAL RESULTS}

To gain insight into the process of compaction localization, experiments (Holcomb and Olsson, 2001) were carried out on specimens of Castlegate sandstone that had been instrumented with 14 transducers so that the acoustic emissions (AE) could be located spatially as well as temporally (Fig. 1). The results substantiated Olsson's (1999) suggestion that compaction bands form and then propagate through the specimen as deformation is applied. It is shown in Olsson and Holcomb (2000) how AE events were, at the yield stress, concentrated in bands laying normal to the maximum compression, near the ends of the specimens and then propagated into the center of specimen with continued applied shortening (Fig. 2). The bands of AE locate the boundary, or compaction front, between compacted and uncompacted material. The fronts move at a velocity that is determined by the velocity of the loading piston and the jump in porosity across the compaction front (Olsson, 2001). Figure 3 shows a plot of the positions of the compaction fronts, taken for simplicity to be that part of the $\mathrm{AE}$ zone with densest concentration of events. Both top and bottom bands start near $50 \mathrm{~mm}$ from the midheight of the specimen, then move with increasing axial shortening. They suggested that the large ratio of elastic modulus of the steel end caps to Castlegate sandstone, approximately 20 to 1 , with the attendant stress concentrations, near the interfaces caused the bands to initiate there (Olsson and Holcomb, 2000). They found that by placing additional friction reducing material on one end of the specimen, band formation could be inhibited or eliminated there.

To capture the rate at which material is being converted from uncompacted to compacted, the composite front is defined as the algebraic sum of the locations of the two real bands. As shown in Figure 3, the velocity of the composite front is 8.3 times the velocity of the piston velocity (shortening rate). This behavior led to the analysis of the propagation of compaction fronts as a shock phenomenon (Olsson, 2001).
A result that is characteristic of Castlegate sandstone that deforms by compaction banding and propagation is the qualitative shape of the stress-nominal strain curve (Fig. 4). We use the idea of a non-local, nominal strain (axial deformation/original length) because once the band appears, the strain is nonuniform. This is simply the deformation normalized with respect to original length. The curve is characterized by a roughly linear region to the yield peak near $\varepsilon_{11}=0.015$, which is always followed by a drop in stress of about 3-5 MPa. The radius of curvature of the yield peak is very small compared to that for specimens that are developing shear fractures at lower confining pressure. The next phase of deformation is associated with the propagation of one or two compaction fronts down the length of the specimen. When two fronts meet at about $\varepsilon_{11}=0.08$, the stress begins to rise. We interpret this as a strengthening associated with densification of the specimen. Qualitatively similar curves have been obtained for localized compaction in Bentheim sandstone (Wong et al., 2001; Klein et al, 2001), and in several materials discussed in the section on non-rock materials.

Thin and thick sections were prepared from a partially compacted specimen of Castlegate sandstone for optical and for scanning electron microscopy (DiGiovanni et al., 2000). Sections were taken from both sides of the compaction front. Beyond the compaction front, where compaction had yet to occur, the grains were undeformed. But, behind the compaction front, the porosity was markedly reduced and the original fabric was completely destroyed by pervasive grain crushing. This extensive grain fragmentation is consistent with the very large number of $\mathrm{AE}$ observed during the experiment.

\section{PERMEABILITY CHANGES DURING COMPACTION FRONT PROPAGATION}

Compaction localization results in a spatially inhomogeneous pattern of deformation, which evolves with time and continued strain. As a result, a number of phenomena related to fluid flow are predicted to accompany compaction localization, including compaction-induced fluid injection, locally increased pore pressures, and spatial changes in the effective permeability. Holcomb and Olsson (2001) discussed the results of experiments combining the use of $\mathrm{AE}$ to track the location of compaction front(s) with continuous measurements of fluid inflow and outflow from specimens of Castlegate sandstone being deformed under triaxial stress conditions.

Propagation of the compaction fronts during a typical experiment is illustrated in Figure 2, which shows the transition from homogeneous deformation pre-peak to localized deformation occurring at two compaction fronts. Compaction localization converts the nominally homogeneous Castlegate to two phases: high permeability sandstone 

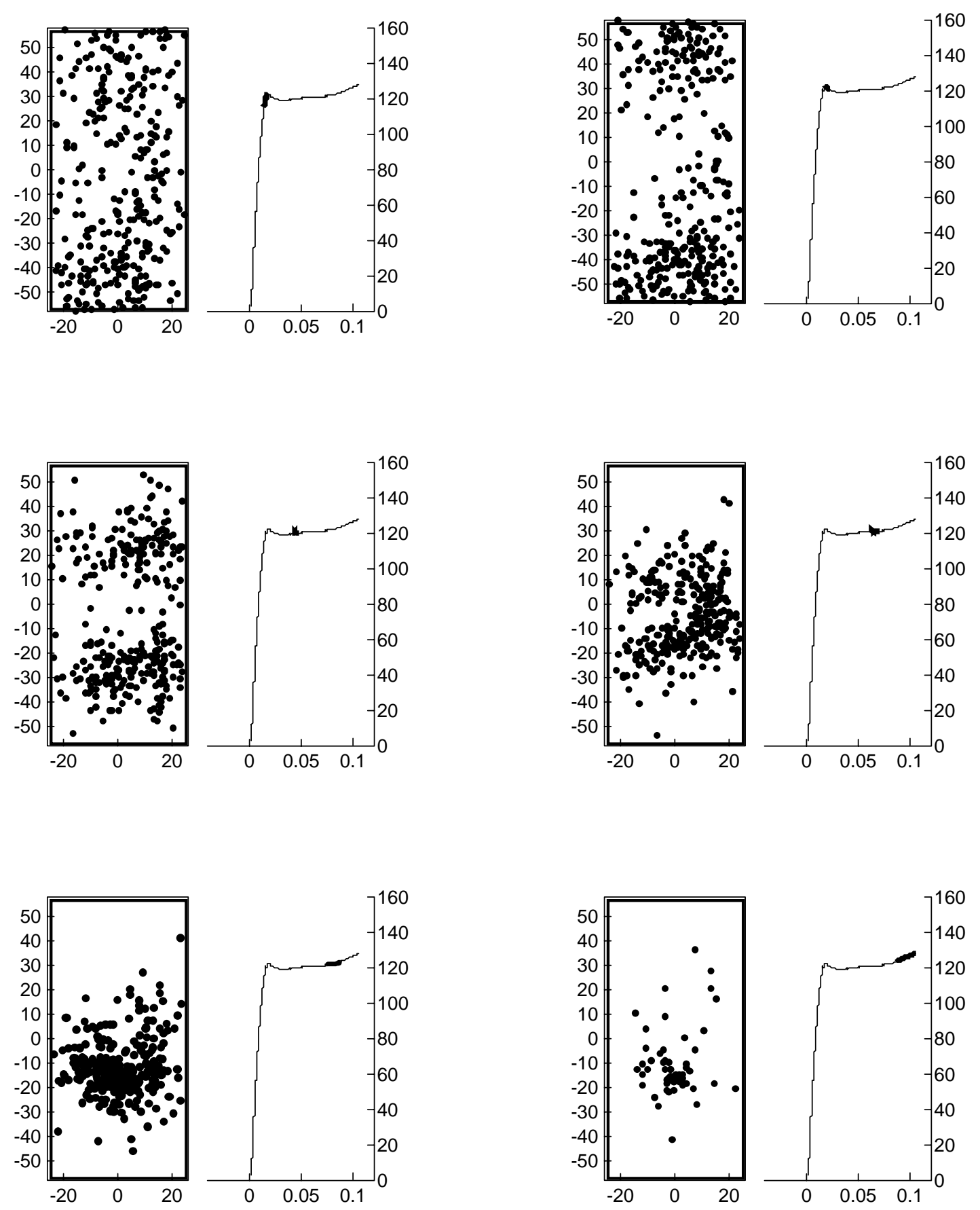

Figure 2

Locations of AE events shown by dots on schematic cross-section of specimen in left-hand panel in each pair. The right-hand panels show axial stress plotted against nominal strain. The thickened region of the stress-strain curve is the window during which the AE events occurred. 


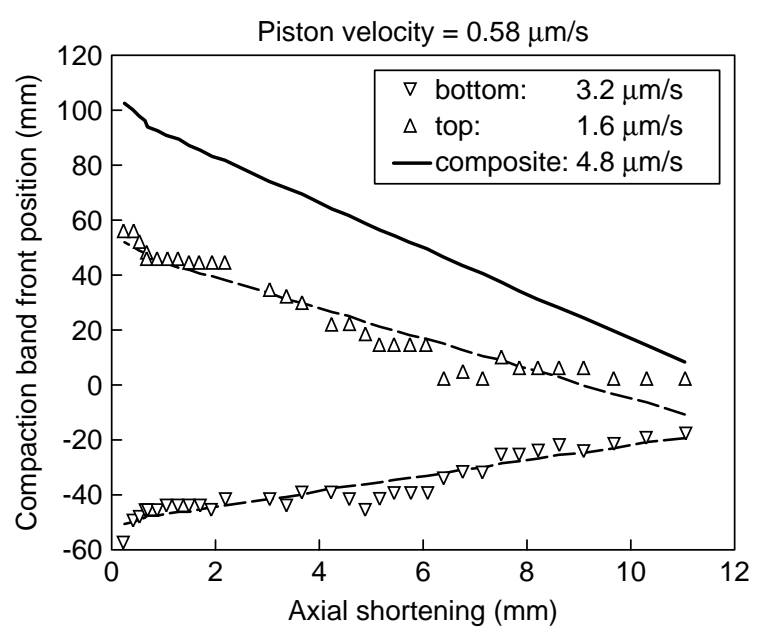

Figure 3

Locations of the compaction zone fronts and the composite zone front plotted against axial shortening. The best-fit velocity data are indicated. The velocity of the composite band is 8.3 times the velocity of the piston.

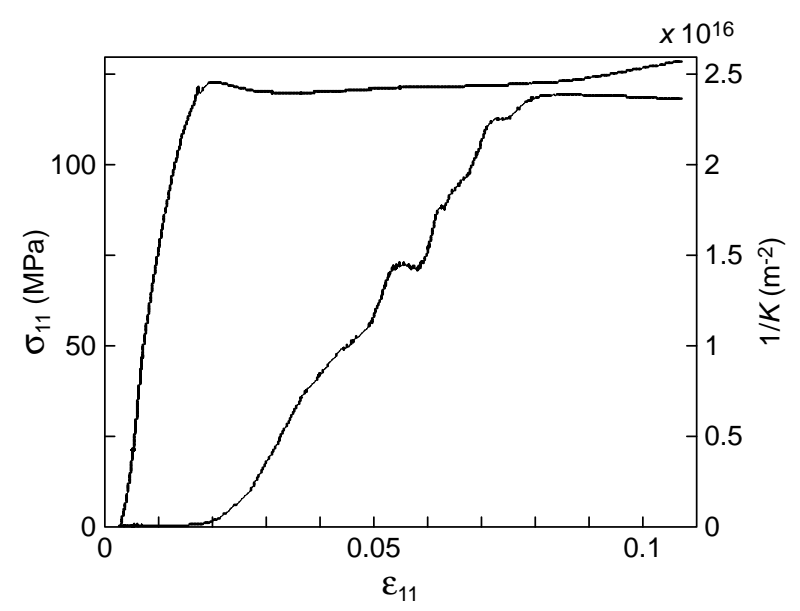

Figure 4

Axial stress and inverse permeability plotted against nominal axial strain. and compacted, low permeability sandstone, separated by the moving boundary of the compaction front(s). Additional time-dependence is introduced by storativity, the dependence of the porosity on local pore pressure, which in turn is determined by the spatially inhomogeneous permeability. A further complication, not yet investigated, is the effect of compaction-induced changes in pore pressure on localization. Changes in effective stress are expected to influence compaction localization in a fashion analogous to the affect of dilatancy hardening on shear deformation and localization.

After the passage of the compaction front, the permeability of the compacted Castlegate sandstone was found to be 2-3 orders of magnitude lower than that of the uncompacted sandstone. Only at the beginning and end of the experiment can the sample be treated as homogeneous. At intermediate states (see Fig. 2) part of the sample has been converted to the compacted form, while the remainder is still in the uncompacted, high-permeability state. Thus for the purposes of permeability measurements, the sample consists of a series assembly of materials differing in permeability by 2-3 orders of magnitude. Reciprocal permeabilites, scaled by the appropriate length of compacted or uncompacted rock, add in series. This leads to the prediction that the reciprocal of effective sample permeability, calculated from flow rate through the sample divided by total pressure difference should increase linearly, in proportion to the amount of the sample that has been converted to the compacted form. In turn, as Figure 3 shows, the conversion from initial to compacted state is a linear function of axial shortening or axial strain. Figure 4 is a plot of stress and the reciprocal of effective sample permeability as a function of axial strain. Because of the large difference in permeabilities between uncompacted and compacted Castlegate sandstone, the reciprocal permeability is essentially zero up to the peak stress, where compaction localization began. During the compaction phase, the reciprocal permeability was found to be a linear function of axial strain, consistent with the model of the sample as consisting of distinct zones of compacted and uncompacted material, with the zone boundary moving at a rate proportional to the strain rate.

The existence of multiple compaction fronts implies that existing pore fluid, plus the extra fluid expressed from the compacting sandstone, will be trapped between low permeability boundaries, resulting in increased pore pressures. In the well-known phenomenon of dilatancy hardening, newly created pore space decreases the pore pressure locally, raising the effective mean stress and slowing or halting the shear localization process. A similar phenomenon is expected in compaction localization, but with the opposite cause. Compaction removes pore space and locally increases the pore pressure, decreasing the effective mean stress. As compaction is largely, but not solely, driven by mean stress, the result should be to slow or halt the compaction process. In addition, on the reservoir scale, this is one possible process for generating over pressures. The analysis of Holcomb and Olsson (2001) shows that the induced pore pressures scale as the sample dimensions, implying that at the reservoir scale large pore pressures can be induced by this mechanism. 


\section{THEORY}

How is the occurrence of localized zones of compaction related to the stress state and the constitutive properties of the rock? Olsson (1999) recognized that this question could be addressed within the same framework used by Rudnicki and Rice (1975) to derive conditions for the onset of shear bands. Rudnicki and Rice (1975) considered an element of homogeneous material subjected to boundary conditions such that further homogeneous deformation is a possible solution. They determined conditions for which the constitutive relation permitted an alternative solution, in particular, one corresponding to localized deformation in a planar band and satisfying conditions of continuing equilibrium. Rice (1976) has given a general treatment of conditions for localization, their relation to more general non-uniqueness and examples for different material models. Here, we briefly outline these conditions as they relate to compaction bands. More detailed descriptions of the application of this theory to compaction bands have been given by Issen and Rudnicki (2000, 2001) and Rudnicki (2002).

The kinematic requirement that the velocity field remain continuous at the inception of localization implies that the difference between the strain-rate in the localized zone and the homogeneous field outside be a combination of simple shear and uniaxial compression or dilation relative to the plane of the band. For a "pure shear band", this difference is simple shear only, without compression or dilation. In geological materials, shear band formation is typically accompanied by dilation or compaction. For a compaction band, the difference in the strain-rate fields is uniaxial compression relative to the plane of the band. In this case, the conditions for localization (Rudnicki and Rice, 1975; Rice, 1976) reduce to the requirement that the stress strain curve for uniaxial compressive strain has a peak or, in other words, that the tangent modulus for this deformation state vanish. This condition is precisely that inferred by Olsson (1999) on the basis of simple one-dimensional considerations. (Although this result is not cited explicitly in Issen and Rudnicki (2000, 2001), the conditions obtained by them for the onset of compaction bands can be put in this form).

Rudnicki (2002) analyzed conditions for the onset of compaction bands for a transversely isotropic constitutive relation intended to model the response of rock in the axisymmetric compression test. For constant lateral confining stress, the slope of the axial stress $v s$. axial strain curve is $E$ and the negative of the ratio of increments of lateral to axial strain is $v$. For purely linear elastic deformation, $E$ and $v$ are equal to Young's modulus and Poisson's ratio, respectively, but, here, they denote incremental values for inelastic deformation. For increments of lateral stress with fixed axial deformation, $r$ is the ratio of axial to lateral stress increments and $K$ is the modulus relating increments of lateral stress and deformation. For purely linear elastic deformation $r$ is equal to twice Poisson's ratio and $K$ can be related to a combination of the shear and bulk moduli, but, here, again, they denote incremental values.

For uniaxial deformation (sample is constrained against lateral deformation), the tangent modulus (ratio of the increment of axial stress to the increment of axial deformation) for this model is $E_{\text {uniaxial }}=E+9 r v K / 2$. Thus, for the usual axisymmetric compression test with constant lateral stress, compaction bands are first predicted to occur when the tangent modulus is $E=-9 r v K / 2$. Although the values of $r, \mathrm{v}$ and $K$ are not well-constrained (Rudnicki, 2002), this prediction is roughly in accord with observations of compaction band formation when $E \approx 0$ or is slightly negative.

The constitutive relation used by Rudnicki (2002) is convenient for axisymmetric deformation states, but relations for geological materials for more general states are typically described in the plane $\tau_{e} v s$. $\sigma$, where $\tau_{e}=\left(\sigma_{i j}^{\prime} \sigma_{i j}^{\prime} / 2\right)^{1 / 2}$ is the second invariant of the deviatoric stress, $\sigma_{i j}^{\prime}=\sigma_{i j}-\delta_{i j} \sigma_{k k} / 3$ and $\sigma=-\sigma_{k k} / 3$ is the mean compressive stress (Fig. 5). The yield surface is the boundary of those stress states causing purely elastic deformation and will evolve with inelastic deformation. The slope of this surface is $\mu$. For low values of the mean compressive stress $\mu>0$ and has the interpretation of a "friction coefficient," but for higher values of $\sigma, \mu<0$. For low porosity rocks, the portion of the surface for which $\mu<0$, which we refer to as the "cap", occurs at such high values of $\sigma$ that it is omitted entirely. For more porous rocks, hydrostatic compression causes inelastic compaction at relatively low values of and the "cap" is an essential element of the constitutive model. In Figure 5, the standard axisymmetric compression test plots as a line with slope $\sqrt{3}$ intersecting the $\sigma$ axis at the value of the lateral confining stress.

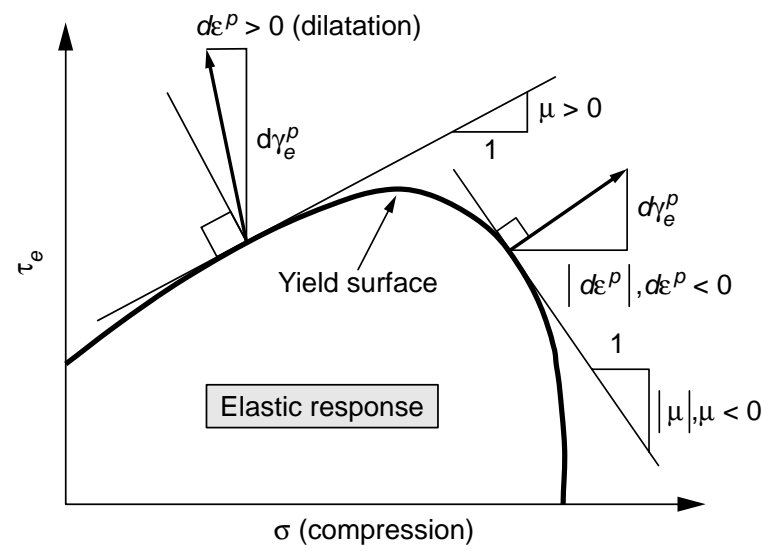

Figure 5

Schematic yield curve with cap exhibited by porous rock. 
The inelastic strain increment $\left(\mathrm{d} \gamma_{e}^{p}, \mathrm{~d} \varepsilon^{p}\right)$, where $\mathrm{d} \gamma_{e}^{p}=$ $\left(2 \mathrm{~d} e^{p}{ }_{i j} \mathrm{~d} e^{p}{ }_{i j}\right)^{1 / 2}, \mathrm{~d} e^{p}{ }_{i j}$ is the deviatoric part of $\mathrm{d} \varepsilon^{p}{ }_{i j}$ and $\mathrm{d} \varepsilon^{p}=\mathrm{d} \varepsilon^{p}{ }_{k k}$ (positive for compression) is shown in Figure 5 as a vector. The ratio of $\mathrm{d} \varepsilon^{p}$ to $\mathrm{d} \gamma_{e}^{p}$ is denoted by $\beta$ which is positive if the inelastic volume deformation is dilation and negative if it is compactant. In Figure 5, the vector $\left(\mathrm{d} \gamma_{e}^{p}, \mathrm{~d} \varepsilon^{p}\right)$ is inclined to the left for dilation and to the right for compaction. Hence, stress states on the "cap" will generally correspond to compaction, although it is possible for $\beta$ and $\mu$ to have opposite signs. Observations of geological materials indicate that this vector is generally not perpendicular to the yield surface where $\mu>0$ but this assumption is often made for the "cap".

Issen and Rudnicki $(2000,2001)$ have repeated the localization analysis of Rudnicki and Rice (1975) for a constitutive relation of the type depicted in Figure 5 but focusing on conditions for compaction band formation. Their analysis incorporates the correction by Perrin and Leblond (1993) of the conditions for which the localized band is perpendicular to one of the principal stresses. (This correction can also be derived from the analysis of Ottosen and Runeson (1991). Issen and Rudnicki (2000, 2001) show that compaction band formation is predicted to occur if the sum $\mu+\beta<-3^{1 / 2}$. In addition, they show that for negative values of $\mu$ and $\beta$, the most favorable deviatoric stress state for compaction band formation is axisymmetric compression. These predictions are generally consistent with observations of compaction bands in highly porous rock with stress states on the "cap". But, precise predictions of the onset of compaction bands and their development require details of the shape of the "cap", its evolution with inelastic deformation and porosity, and the nature of its connection to the shear yield surface. At present, only limited experimental observations are available to constrain these details.

Figure 5 shows the slope of the yield surface smoothly changing from positive to negative values, but frequently models (Dimaggio and Sandler, 1971; Fossum and Fredrich, 2000) use two surfaces, a shear yield surface with $\mu>0$ and a "cap" with $\mu<0$, that intersect with a finite vertex angle. Issen (2001) has given an approximate analysis of conditions for compaction band formation at such a vertex. She shows that constitutive parameters inferred from Olsson's (1999) experiments in which compaction bands are observed are consistent with the two-surface model but not with the onesurface model. Also, Wong et al. (2001) report that their observations rule out a constitutive model that does not include multiple deformation mechanisms that could be modeled by multiple surfaces.

Strain localization theory applies up to the actual formation of a compaction front. Beyond that, this theory says nothing. The observation that the compaction fronts moved in proportion to the motion of the end of the specimen (Fig. 3) suggested that an analysis parallel to shock wave theory was appropriate (Olsson, 2001). The piston displacement rate was $0.58 \mu \mathrm{m} / \mathrm{s}$ and the summed velocity of the two compaction fronts was $4.8 \mu \mathrm{m} / \mathrm{s}$, giving a ratio of front velocity to piston velocity of 8.3. Because of the low velocities, one of the three Hugoniot equations, the momentum balance, disappears leaving only the mass and energy balance equations. This analysis showed that the ratio of compaction front velocity $v_{f}$ to piston velocity $v_{p}$ is equal to $(1-P) /\left(P_{o}-P\right)$, where $P$ is the compacted porosity and $P_{o}$ is the uncompacted porosity. The microstructural studies indicated that the compacted porosity $P$ was about 0.21 . Using $P_{o}=0.28$ gives a predicted ratio of front velocity to piston velocity of $v_{f} / v_{p}=11.3$, or approximately a $30 \%$ difference between a simplified model and the data. The model also explains the consistent, small stress drop associated with the formation of the band.

\section{IMPLICATIONS OF DIFFERENCES IN LABORATORY OBSERVATIONS}

Discrete, non-propagating compaction bands have been observed in Bentheim sandstone (Wong et al., 2001; Klein et al., 2001). Deforming this rock in triaxial compression in the confining pressure range from 120 to $300 \mathrm{MPa}$ results in stress-deformation curves with a saw-tooth appearance. The resulting specimens contain numerous thin, somewhat wavy, compaction bands that are clustered near the end one-third regions. These workers believe that the drops in the stressdeformation curve are associated with the individual bands. In the specimens of Castlegate sandstone that exhibited (propagating) compaction bands (Olsson and Holcomb, 2000) there is no evidence of individual bands, and the stress-deformation curves are smooth in the region of band propagation.

This difference between the deformation modes of the two sandstones, Castlegate and Bentheim, may hold clues as to the parameters governing the origin of compaction bands. Wong and coworkers (Wong et al., 2001; Klein et al., 2001) do not mention the orientation of their specimens with respect to the loading direction, but the standard practice in compression testing is to compress normal to bedding. Olsson and Holcomb (Olsson, 1999; Olsson and Holcomb, 2000) deformed their specimens parallel to bedding. Thus orientation may be an important parameter governing the style of compaction banding.

Correlation of the episodes of stress-drop with formation of discrete compaction bands (Wong et al., 2001; Klein et al., 2001) suggests that the intercalated compaction zones expanded in much the same way as the smooth zones such observed by Olsson and Holcomb (2001). Clearly, the type of band formation, discrete versus smooth, would have important ramifications in reservoir mechanics. 


\section{CONNECTIONS TO NON-ROCK MATERIALS}

It is important for the eventual understanding of the origin of compaction bands and propagating zones of compaction to realize that apparently very similar processes operate in materials of completely different structure and composition.

In closed-cell aluminum alloy foam (Bastawros et al., 2000), wavy, narrow compaction bands formed, hardened and then ceased to thicken. More bands are formed at higher specimen deformations. The figures look remarkably similar to those of discrete compaction bands in sandstone described by Klein et al. (2001) and Wong et al. (2001).

Other materials that exhibit propagating compaction zones are polycarbonate honeycombs (Papka and Kyriakides, 1998) and steel foam (Park and Nutt, 2001).

Evidently all materials that yield by formation and propagation of compaction zones, exhibit the same type of stress-deformation curve; this curve seems to be an indicator of the compaction band process, as well as the Lüders band mechanism.

\section{IMPLICATIONS FOR RESERVOIRS}

Three styles of compaction have now been recognized:

- uniform compaction;

- thin discrete, stationary compaction bands, and

- propagating compaction zones.

Uniform compaction is widely recognized and can cause casing failures, seafloor subsidence, it can squeeze oil from the rock into the borehole, or significantly decrease the permeability of the reservoir rock, thereby reducing production .

New field and laboratory observations suggest that the picture can be much more complicated than simple, uniform compaction. Mollema and Antonellini (1996) have described thin, natural, tabular zones of compaction in certain types of sandstone. At the small scale these features can interfere with fluid flow when present in reservoir rock. One may consider how naturally occurring compaction bands, especially when combined with deformation (shear) bands, could severely compartmentalize an oil-bearing sandstone.

New laboratory work has shown a heretofore-unknown deformation mechanism in porous rock: propagation of compaction zones normal to the direction of maximum compression (Olsson, 1999; Olsson and Holcomb, 2000; Olsson, 2001). Furthermore, the effect of propagation of compaction bands on the apparent permeability of the compacting specimen has been illustrated (Holcomb and Olsson, 2001). Recently, Wong and coworkers (Wong et al., 2001; Klein et al., 2001) have shown yet another mode of compaction wherein the successive appearance of discrete compaction bands is accompanied by a saw-toothed stressdeformation relation. Clearly, if these processes occur on the scale of a producing reservoir as a result of increased effective stresses attendant upon draw-down, then one would expect smooth compaction propagation to affect the production in a much different way than the successive formation of discrete bands. The first may tend to squeeze oil out much more efficiently than uniform compaction because the porosity of the rock through which some oil flows is not decreased. Contrarily, compaction of a reservoir by spreading zones of discrete compaction bands intercalated with uncompacted rock would act as a trapping mechanism.

The formation by the compaction banding mechanism of borehole breakouts as observed by Haimson and his coworkers (Haimson and Song, 1998; Kovacich and Haimson, 2000; Haimson, 2001) presents a possible source of sand production as well as a means of greatly altering fluid flow paths near boreholes.

\section{REFERENCES}

Antonellini, M. and Aydin, A. (1995) Effect of Faulting on Fluid Flow in Porous Sandstones: Geometry and Spatial Distribution. Am Assoc. Petrol. Geol., 79, 642-671.

Bastawros, A.F., Bart-Smith, H. and Evans, A.G. (2000) Experimental Analysis of Deformation Mechanisms in a ClosedCell Aluminum Alloy Foam. J. Mech. Phys. Solids, 48, 301-322.

Besuelle, P. (2001) Compacting and Dilating Shear Bands in Porous Rock: Theoretical and Experimental Conditions. $J$. Geophys. Res., 106, 13435-13442.

Bessinger, B.A., Liu, Z., Cook, N.G.W. and Myer, L.R. (1997) A New Fracturing Mechanism for Granular Media. Geophys. Res. Lett., 24, 2605-2608.

DiGiovanni, A.J., Fredrich, T., Holcomb D.J. and Olsson, W.A. (2000) Micromechanics of Compaction in an Analogue Reservoir Sandstone. In Pacific Rocks 2000, Girard, J., Liebman, M., Breeds, C. , Doe, T. (eds.), Balkema, Rotterdam.

Dimaggio, F.L. and Sandler, I.S. (1971) Material Model for Granular Soils. J. Engn. Mech., ASCE, 97, 935-950.

Fossum, A.F. and Fredrich, J. T. (2000) Cap Plasticity Models and Compactive and Dilatant Pre-Failure Deformations. In Pacific Rocks 2000, Girard, J., Liebman, M., Breeds, C., Doe, T. (eds.), Balkema, Rotterdam.

Haimson, B.C. and Song, I. (1998) Borehole Breakouts in Berea Sandstone: Two Porosity-Dependent Distinct Shapes and Mechanisms of Formation. In Rock Mechanics in Petroleum Engineering, Soc. Petrol. Eng., Richardson.

Haimson, B.C. (2001) Fracture-Like Borehole Breakouts in HighPorosity Sandstone: Are they Caused by Compaction Bands? Phys. Chem. Eart (A), 26, 15-20.

Holcomb, D.J. and Olsson, W.A. (2001) Compaction Localization and Fluid Flow. Submitted to J. Geophys. Res.

Issen, K.A. and Rudnicki, J.W. (2000) Conditions for Compaction Bands in Porous Rock. J. Geophys. Res., 105, 21529-21536.

Issen, K.A. and Rudnicki, J.W. (2001) Theory of Compaction Bands in Porous Rock. Phys. Chem. Earth (A), 26, 95-100.

Issen, K.A., (2001) The Influence of Constitutive Models on Localization Conditions for Porous Rock. Engn. Frac. Mech., to appear. 
Klein, E., Baud, P., Reuschle, T. and Wong, T.f. (2001) Mechanical Behaviour and Failure Mode of Bentheim Sandstone under Triaxial Compression. Phys. Chem. Earth (A), 26, 21-25.

Kovacich, J.R. and Haimson, B.C. (2000) Factors Affecting Borehole Breakout Dimensions, and the Potential for Sand Production in High Porosity Berea Sandstone. In Pacific Rocks 2000, Girard, J., Liebman, M., Breeds, C., and Doe, T. (eds.), 1153-1160, Balkema, Rotterdam.

Lajtai, E Z. (1974) Brittle Fracture in Compression. Int. J. Fract., 10, 525-536.

Mollema, P.N. and Antonellini, M.A. (1996) Compaction Bands: A Structural analog for anti-mode I cracks in aeolian sandstone. Tectonophysics, 267, 209-228.

Olsson, W.A. (1999) Theoretical and Experimental Investigation of Compaction Bands in Porous Rock. J. Geophys. Res., 104, 7219-7228.

Olsson, W.A. and Holcomb, D.J. (2000) Compaction Localization in Porous Rock. Geophys. Res. Letters, 27, 35373540 .

Olsson, W.A. (2001) Quasistatic Propagation of Compaction Fronts in Porous Rock. Mech. Mat., 33, 659-668.

Ostermeier, R.M. (2001) Compaction Effects on Porosity and Permeability: Deepwater Gulf of Mexico Turbidites. J. Pet. Tech., February, 68-74.
Ottosen, N.S. and Runesson, K. (1991) Properties of Discontinuous Bifurcation Solutions in Elasto-Plasticity. Int. J. Solids Struct., 27, 401-421.

Papka, S.D. and Kyriakides, S. (1998) In-Plane Crushing of a Polycarbonate Honeycomb. Int. J. Solids Struct., 35, 239-267.

Park, C. and Nutt, S.R. (2001) Anisotropy and Strain Localization in Steel Foam. Mat. Sci. Eng., A299, 68-74.

Perrin, G. and LeBlond, J.B. (1993) Rudnicki and Rice's Analysis of Strain Localization Revisited. J. Appl. Mech., 60, 842-846.

Rice, J.R. (1976) The Localization of Plastic Deformation. In Proc. $14^{\text {th }}$ IUTAM Congress, Koiter, W. (ed.), North Holland.

Rudnicki, J.W. (2002) Conditions For Compaction and Shear Bands in a Transversely Isotropic Material. Int. J. Solids Struct., 39, 3741-3756.

Rudnicki, J.W. and Rice, J.R. (1975) Conditions for the Localization of Deformation in Pressure-Sensitive Dilatant Materials. J. Mech. Phys. Solids, 23, 371-394.

Wong, T.f., Baud, P. and Klein, E. (2001) Localized Failure Modes in a Compactant Porous Rock. Geophys. Res. Lett., 28, 2521-2524.

Final manuscript received in June 2002 